\title{
Designing the Expanded Programme on Immunisation (EPI) as a service: Prioritising patients over administrative logic
}

\author{
Jacob McKnight ${ }^{\mathrm{a} *}$ and Douglas B. Holt ${ }^{\mathrm{b}}$ \\ ${ }^{a}$ Oxford Health Systems Collaboration - Africa (OHSCAR), Nuffield Department of Medicine, $\quad \mathrm{AQ1}_{1}$ \\ University of Oxford, Oxford, UK; ${ }^{b}$ Department of Marketing, University of Southern Denmark and \\ Cultural Strategy Group, Boulder, CO, USA
}

(Received 3 October 2013; accepted 10 July 2014)

\begin{abstract}
Expanded Programme on Immunisation (EPI) vaccination rates remain well below herd immunity in regions of many countries despite huge international resources devoted to both financing and access. We draw upon service marketing theory, organisational sociology, development anthropology and cultural consumer research to conduct an ethnographic study of vaccination delivery in Jimma Zone, Ethiopia - one such region. We find that Western public health sector policies are dominated by an administrative logic. Critical failures in delivery are produced by a system that obfuscates the on-the-ground problems that mothers face in trying to vaccinate their children, while instead prioritising administrative processes. Our ethnographic analysis of 83 mothers who had not vaccinated their children reveals key barriers to vaccination from a 'customer' perspective. While mothers value vaccination, it is a 'low involvement' good compared to the acute daily needs of a subsistence life. The costs imposed by poor service - such as uncaring staff with class hostilities, unpredictable and missed schedules and long waits - are too much and so they forego the service. Our service design framework illuminates specific service problems from the mother's perspective and points towards simple service innovations that could improve vaccination rates in regions that have poor uptake.
\end{abstract}

Keywords: immunisation; service design; marketing; EPI; vaccination

\section{Designing the Expanded Programme on Immunisation (EPI) as a service}

Under the rubric of the EPI, a wide variety of Western governmental and nongovernmental organisations in the global public health sector have worked intensively over the past 40 years to improve routine vaccination rates in the world's poorest countries. Historically, poor vaccination rates in the EPI countries were linked to problems concerning geographic and financial access to the vaccines. Vaccines often spoiled due to malfunctioning cold chains, clinics suffered frequent stock-outs due to inadequate transportation networks and poor logistical planning, and the distance required to travel to access points was often insurmountable for people in remote rural areas (Cheyne, 1989). In response, the global public health sector has worked with the health ministries in many of the EPI countries to make significant 'hard' infrastructure investments such as building rural health clinics, supplying and maintaining refrigeration units and funding missing transportation links in the supply chain. More recently, in the

\footnotetext{
*Corresponding author. Email: jacobmcknight@gmail.com 
era of interventions dominated by the The Global Alliance for Vaccines and Immunizations (GAVI), policy has focused on lowering the effective price of vaccination for governments by creating a financing mechanism to pay for the vaccines. This important work continues today, for implementation on such an enormous scale is never finished. However, from a strategic standpoint, the focus of the global public health sector has clearly shifted.

Early evaluations of GAVI highlighted a major gap that access-oriented policies had missed: the limited capacity of national public health systems to deliver on the 'soft' management aspects of vaccine delivery (Brugha, Starling, \& Walt, 2002; McKinsey and Company, 2003). As a result, to address this significant remaining gap, the global public health sector has expended tremendous effort over the past decade to improve the management of vaccination delivery through administrative reforms. Many of the major global public health organisations working on EPI vaccination - including the WHO, GAVI, UNICEF, CARE, The Bill and Melinda Gates Foundation and national development agencies such as USAID and Department for International Development (DFID) - have worked with the national health ministries in the EPI countries to make a significant push to implement reforms that address a variety of management problems (GAVI, 2005a, 2005b).

The resulting improvements in vaccination rates due to these access and administrative initiatives have been extraordinary by any measure. However, significant regions in a number of major EPI countries - including Nigeria, Congo, Ethiopia, India, and Indonesia - are still vaccinating at rates well below herd immunity levels. Childhood mortality rates continue to lag significantly behind the United Nations' Millennium Development Goals in most sub-Saharan countries and parts of South and South-east Asia (Rajaratnam et al., 2010). Insufficient vaccination rates are one important cause of these early deaths.

Our study seeks to conceptualise why low vaccination rates persist in some regions despite tremendous long-term investments in access and administrative policies. We draw upon frameworks from organisational sociology, medical anthropology, marketing and consumer research to open up a new strategic direction for vaccine delivery that we hope can lead to another step-change improvement in vaccination rates. We do so through an ethnographic study of vaccination delivery in Jimma Zone, Ethiopia. We analyse this immunisation programme as a market system, and dissect the service failures of this system using what in marketing is called service design, which focuses on improving delivery from the perspective of the client - mothers with infants. Our analysis reveals that these service weaknesses result from the domination of what we term an administrative logic. Service failures are systematically produced, rather than being idiosyncratic gaps in an otherwise successful programme. Both the international organisations and the domestic government agencies devoted to reforming the vaccination system intensively focus on administrative procedures, which has the unintended consequence of systematically obscuring the struggles that mothers face in trying to vaccinate their infants. Our service design approach provides a corrective measure: a systematic method to illuminate service problems faced by mothers, which points towards specific design innovations to correct these problems.

\section{Theory and methods}

We study vaccination as a particularly challenging service design problem (Berry, 1995; Berry \& Parasuraman, 1991). Analysing non-vaccination from a service design 
perspective entails conceiving of the mothers of infants as customers, and carefully analysing why the existing service design limits their participation (Cottam \& Leadbetter, 2004; Thomas, 2008). Marketing theory focuses on designing the offering - the delivery of vaccines to young children - to optimise the 'value proposition' (in this case, improving access) to customers (the mothers of these children). We analyse immunisation delivery as a market system that should be designed to minimise hurdles. We use careful inductive research of mothers who have not vaccinated in order to illuminate significant gaps in service design. The final step in the process is to design service innovations that specifically address the service failures and experiment with these changes until the failure is corrected. We offer several illustrative examples at the end of the study.

This approach differs from the way that marketing is typically understood and used in public health (as 'social marketing'): as a set of techniques to generate demand for vaccination and other public health outcomes. The standard social marketing approach overlooks some of the most important insights from marketing theory that can inform improvements to vaccination delivery: not just generating demand but optimising how a public service is designed through systematic analysis of how customers interact with the existing 'marketing system' to detect deficits.

We adapt the theory and methods of ethnographic consumer research to identify failures in the delivery of immunisation that are missed by the administrative logic employed by the global public health organisations (Burawoy, 1998). Consumer research shares with medical anthropology a focus on the local cultural understandings and practices of public health 'customers' (Leach \& Fairhead, 2007; Nichter, 1995; Streefland, Chowdhury, \& Ramos-Jimenez, 1999). It is distinctive in its strategic focus on how to improve the value proposition of the public health intervention. We analyse the interactions between local public health 'customers' and specific components of the public vaccine delivery system with the aim of dissecting weaknesses in service provision. Applying our services marketing lens, we ask: what are the flaws in the design and implementation of the 'service offering' (the delivery of vaccines to young children) that subverts the perceived value of vaccination to its 'customers' (mothers of these children)?

To unpack the current immunisation system's tacit but systematic 'refusal' to see the weaknesses of vaccination delivery from the perspective of mothers with infants, we draw on the critical development anthropology literature that documents how development agencies systematically overlook the views of their would-be 'beneficiaries'. For instance, Ferguson's (1994) analysis of the 'bovine mystique' demonstrated how AQ2 dominant development narratives can systematically ignore the views of aid 'beneficiaries'; Farmer (1996, 2004) documented the structural violence imposed by health delivery systems not attuned to the needs of their users; and Nguyen (2010) draws upon Foucault's biopower to show how the administration of HIV antiretrovirals in West Africa creates a system in which access to drugs is exchanged for stories of sickness. Similarly, Judith Justice (1986) and Svea Closser (2010) have explored the disparities that emerge between processes of planning and accounting in global public health that tend to ignore or undermine the views of 'beneficiaries'.

Our study examines vaccine delivery in Jimma Zone, Ethiopia, with ethnographic field research extending from 2007 through 2010. We selected this site because Ethiopia was one of the most significant EPI countries struggling with low vaccination rates in many regions despite massive international investments. Jimma Zone is a large and heavily populated area of Oromia region, which at the time of the research had the largest absolute number of unvaccinated children in Ethiopia. Jimma Zone provided a good 
cross-section of the different kinds of service delivery contexts in Ethiopia: from urban areas delivered by large health centres, to health posts serving villages and rural areas, to outreach programmes aimed at small, distant communities.

We pursued two types of field data collection and analysis. Our initial fieldwork examined the existing vaccine delivery system in Jimma Zone, with a particular focus on the major reform efforts led by the Western global public health sector. The first author completed four fieldwork trips, comprising a total of five months of observation, interviews and archival data collection. He conducted extensive interviews with managers from UNICEF, the WHO and the Ethiopian Ministry of Health $(\mathrm{EMoH})$ responsible for vaccination delivery, and with many public health workers who were directly responsible for delivering vaccination services. We mapped vaccine delivery as a marketing system across all of the relevant actors and activities from the national level down to the lowest kebele level, examining how reform efforts were impacting vaccination services on the ground.

Following the Extended Case Method (Burawoy, 1998), we analysed the findings of our data relative to existing theory and then used this analysis to inform the second phase of research, which consisted of ethnographic interviews with mothers who had not vaccinated an eligible child. Our sampling frame was guided by our goal to induct a customer-centric model of immunisation barriers that are embedded in the vaccine service delivery system. We pursued analytic sampling (Glaser \& Strauss, 1968) in which we sought to investigate the diverse range of vaccination contexts within Jimma Zone. We selected three low-performing woredas (mid-level administrative zones encompassing a small town or a large area of the countryside) that varied in terms of economic development. Two woredas were rural and one was urban. Within each woreda, we sampled from a range of kebeles (neighbourhoods, the smallest administrative unit in Ethiopia) that differed in terms of geographic access to a health facility. In each kebele, we located informants through a combination of methods that the context allowed for: typically door-to-door requests, introductions at markets and snowball sampling. Our final sample totaled 83 interviews, which far exceeds typical sample sizes used in qualitative market research to detect redundant patterns in the data (Griffin \& Hauser, 1993).

We used ethnographic interview techniques (McCracken, 1988), which rely heavily on active listening and directive probing, to encourage mothers to tell detailed stories about their own vaccination service experiences, and stories about family and friends that are part of the local discourse (Thompson, 1997). Prior to data collection, our research design was approved by our university's ethics committee. The first author trained two female graduate students from the local university to conduct the interviews in Oromifa or Amharic, according to the preference of the respondent. He accompanied the interviewers to informants' homes, where the interviews were conducted, and made field observations along with the interviews and also collected basic demographic data for each informant. We recorded the interviews and had them translated and transcribed for our analysis. Prior to each interview, we received informed consent from the participants, who were assured that their remarks would remain confidential.

Mothers who had vaccinated their older children told stories about their first-hand experiences. Many more mothers referenced stories that had been told to them by friends and family. In addition, many comments reflected the local discourse on vaccinating and, so, were reported as generalised taken-for-granted 'truths' rather than a specific story. We analysed these accounts using the hermeneutic methods of cultural consumer research (Thompson, Pollio, \& Locander, 1994). 


\section{The administrative logic of EPI reform}

As we began to uncover a range of barriers to immunisation using our service design perspective, we came to understand that these barriers were a tacit structural feature of the major reform efforts led by Western global public health organisations, rather than isolated design flaws. So, as we mapped out the service design issues, concurrently we also explored in our fieldwork how these barriers remained invisible despite the massive resources focused on improving vaccination rates. This part of the analysis revealed that the recent reforms were uniformly structured by what we will term an administrative logic.

To address the shortcomings of the earlier access-focused strategy, GAVI and its sister global public health organisations instituted a range of new programmes that sought to diffuse Western management technologies into the public health systems of EPI countries. This administrative logic pervades the most influential, ambitious, and well-funded initiatives launched in the last decade: GAVI's Immunisation Services Support (ISS) and Health System Strengthening (HSS) programmes, and the WHO and UNICEF programme called Reach Every District (RED). Other programmes that have addressed specific vaccine management issues include the orchestration of the vaccine supply chain (e.g. Project OPTIMIZE), improving service to remote populations (e.g. Sustainable Outreach Services) and budgeting and planning (e.g. the Comprehensive Multi-Year Planning programme). These reforms were not simply imposed from the outside. Rather, Tedros Adhanom Ghebreyesus, the former Minister of Health, had actively pursued aggressive New Public Management-style reforms that prioritised Western managerial ideology and techniques (Donnelly, 2011).

GAVI launched ISS in 2000 as a performance-based financial incentive paid to countries to improve their immunisation rates. The scheme is simple: for each additional child immunised (compared to the prior year), the country receives $\$ 20$. The programme's intent is to provide the state's public health bureaucracy with an economic incentive to manage its vaccination delivery with a singular focus on improving immunisation performance without imposing a top-down process for so doing. Because this funding was administered at the highest reaches of the public health bureaucracy, we found no discernible impact on the ground amongst vaccination workers, who had no knowledge of it. Rather, its impact was primarily to incentivise senior administrators within the Ministry of Health to carefully measure, monitor and manage their immunisation statistics.

GAVI launched HSS in 2006 as a major grants programme to make significant system-wide investments in national health systems that would lead to a step-change improvement in vaccine delivery (along with other basic health services). The funding for HSS dwarfs all other sources of technical assistance to improve vaccination delivery. In 2009, GAVI committed to an additional $\$ 900$ million in HSS funding, on top of the initial $\$ 500$ million funding pool (GAVI, 2010). During our research, Ethiopia received an HSS grant totalling more than $\$ 76$ million over three years. Applications for HSS funding have to meet criteria stipulated by GAVI which, in addition to the historic focus on hard infrastructure investments, included two key management reform criteria (GAVI, 2008):

- Health work force mobilisation, distribution and motivation targeting personnel engaged in immunisation and other health services at the district level and below.

- Organisation and management of health services at the district level and below (including financial management). 
GAVI encourages national health ministries to write applications that make use of Western management, measurement and control techniques intended to improve oversight of the vast numbers of public employees spread throughout the country delivering immunisations (GAVI, 2007). For instance, one HSS report describes the 'dashboard' of key metrics that managers were supposed to routinely measure and monitor - an adaptation of the 'balanced scorecard' approach that has been an extremely popular management control technique in the USA for the past two decades. HSS has also prodded countries through its grants to adopt a 'harmonised platform,' which is essentially a standardised reporting format for health delivery plans, budgets and metrics (GAVI, 2010).

The RED programme has been the centrepiece of WHO/UNICEF vaccination interventions since its inception in 2002 (GAVI, 2002). The central purpose of RED is to encourage public health managers to use a simple set of management planning tools, referred to locally as 'microplanning.' Managers at health centres and health outposts are asked to fill out a yearly plan, which consists of setting specific vaccination coverage goals and expenses. They are then asked to track ongoing vaccinations on a monthly basis against their plan, and make adjustments in their efforts in areas where vaccinations are lower than projected.

A zonal health team, funded and coordinated by UNICEF or WHO, oversees this planning through an annual meeting with senior woreda health workers. Regional officers from UNICEF or WHO assist the health workers in filling out the microplan documents, usually using their previous plan as a guide for costs and population sizes, rather than any sort of proactive assessment of barriers to immunisation. In addition to the plans and budgets, the health workers are given a page to enter the common problems they experience - most often relating to lack of per diem payments, staff attrition and a lack of budget - and asked to discuss these problems briefly with the regional officers. In our observations, the officers gave this section little attention, focusing instead on the vaccination numbers and budgets.

Following the meetings, health workers return to their woredas and file their RED microplans, which are to be compiled at the zone level and then forwarded to the regional coordinators. The first author spent several weeks conducting field research at the Oromia Regional Health Bureau to understand just how these RED documents were incorporated into the planning process. In all of his observations, the documents were entirely ignored. Administrators had trouble locating the documents for him. Many of the zones had not filed a current RED plan, or had not properly completed the documents that were handed in. Administrators had no system in place to incorporate the documents into their planning activities, demonstrated no interest in conducting any sort of analysis of these documents and certainly were not relying on RED to motivate changes in the design of the vaccination programme. As a WHO coordinator told him, the central purpose of RED is to 'exercise the planning process' - the act of preparing a plan was understood as a fundamental step towards good management. In our observations, completing the RED microplanning forms was perceived by Ethiopian public health managers to be a trivial ritual that they were required to perform for the global public health organisations.

Drawing upon the development anthropology literature, we sought to explain how it is that a consortium of well-intentioned domestic agencies and Western partners systematically produced a 'blindness' to service failures despite their reform mandate. The Western global public health sector involved in EPI is dominated by a pervasive ideology that the best route to improve vaccine delivery is to impose modern management, measurement and control techniques. To conceptualise this taken-for-granted belief, which is 
deeply embedded in the discourse and practices of the sector, we adapt the organisational sociological construct institutional logic (Lounsbury \& Crumley, 2007). To conceive of an institution in terms of its 'logic' simply means that we want to view of the institution as a cultural form: how its ideology powerfully organises how people within the institution understand goals, define problems, pursue the work that needs to be done, measure success and so on. Moreover, we witnessed how this reform ideal - the vision that application of 'professional' Western management technologies will allow for effective measurement and control of all vaccination work - acts as a particular mode of social control, which Foucault terms governmentality (Foucault, Burchell, Gordon, \& Miller, 1991). Through practices of accounting, measuring and planning, the $\mathrm{EMoH}$ and their global health partners assert their right to administer paternalistic oversight (Scott, 1998). Leveraging its extraordinary funding levels and technical expertise, the global public health sector directs how every substantial component of the vaccination programme throughout all links in the national health system should be organised through its administrative logic, while sustaining the politically crucial rhetoric that the public health system is still managed at the local level by the state's health ministry.

The major grants programmes drive this administrative logic into localities through powerful economic incentives. And, just as important, this logic is deeply woven into the non-stop consulting and training that these organisations provide as they advise health ministries on many facets of vaccine policy and implementation, to the extent that we found several instances in which these organisations had ghost-written major national vaccination policy documents.

In its implementation, this administrative logic treats vaccine delivery as a closed 'production system' that can be teased apart into its component processes using technical criteria, and then each of these processes can be optimised through the application of modern management techniques. Reform efforts seek to quantify and measure all aspects of the vaccination delivery process that can be turned into some sort of metric. Analyses of existing management systems seek to pinpoint these management weaknesses and design appropriate administrative reforms. Once the reform is implemented, evaluation studies are conducted to measure whether the population in need of vaccination (typically mothers of infants) have responded to the reform as predicted.

From the viewpoint of our service design lens, what is particularly notable about this administrative logic is the way in which it systematically brackets out the actual customers for this service - mothers with infants. The Ethiopian reform effort used conventional surveys to 'know' their customers. While such surveys can increase understanding of the prevalence of known factors driving low rates of childhood vaccination (Sanou et al., 2009; Wiysonge, Uthman, Ndumbe, \& Hussey, 2012), they are particularly flawed when it comes to illuminating new or unknown factors. Mothers' input into the immunisation management systems is limited to an add-on 'tick the box' section of the cluster surveys that are used to assess vaccination rates. Mothers are asked to tick their 'reasons for not vaccinating.' Yet, because these categories (e.g. 'unaware of the need for immunisation', 'unaware of the need to return') are terribly vague and have been concocted by administrators, they do not allow researchers to discover problems with the current service design and implementation. Regardless, the answers to these questions were filed away and had no influence on policy-making.

We do not intend to evaluate the relative success of these administrative reforms, which is outside the scope of our study. Rather, the point we wish to make is this: the unintended consequence of the dominance of the administrative logic is to institutionalise 'doing modern administration' as the only effective path through which vaccination 
delivery will improve. The hegemony of this managerial ideology blinds global public health organisations and their partners in national ministries of health to alternative approaches that could better address the remaining gaps in immunisation. From our marketing lens, what is noticeably absent in this approach is any sort of effort to design the vaccination system to fit the understandings, constraints and social practices of the 'customer' - the mothers who must bring in their infants to be vaccinated.

\section{Getting infants vaccinated: the customers' view}

We designed the second phase of our research - in-home ethnographic market research interviews with mothers who did not immunise their children - to identify barriers in service delivery that impeded vaccination. We analysed our informants' discussions of vaccination through three complementary lenses: their cultural model of vaccines, the place of infant vaccination in their conceptions of household responsibilities and goals and the process of getting their infants vaccinated.

\section{Active demand for vaccines}

Mothers' failure to vaccinate their infants cannot be attributed to disbelief in the efficacy of the vaccines. While their cultural model of vaccines - the shared, taken-for-granted local understandings of what a vaccine is and its effect on those who are vaccinated differed significantly from the Western scientific model, the vast majority of mothers nonetheless evinced an 'active demand' for vaccines (Nichter, 1995).

Mothers value vaccination as much for giving their children strength and vitality and helping them grow as for defending against disease. They occasionally declared that vaccines cure disease as well: one mother told us about how a polio vaccine had cured her son's paralysed leg. Mothers formed heuristic judgements of the vaccine's efficacy by evaluating the weight, size and visible energy of their children before and after immunisation (Leach \& Fairhead, 2007).

Mothers described the effects of the vaccine as a battle. They believed that vaccines literally combat disease: the pain of vaccination was interpreted as proof of the worth of the vaccine, and diarrhoea was perceived as the discomfiture and defeat of the disease in a bodily form. Vaccination was seen to be a protective force, an intervention that helped the body to fight disease that may be active or dormant in the body. They specified the causal mechanisms of vaccination using metaphors emphasising that with vaccines, diseases cannot 'catch' or 'penetrate' the body.

Overall, the mothers revealed positive preferences towards vaccinating stemming from this local vaccine culture, with its prophylactic, strength and curative properties. Our research identified areas of understanding where mothers would benefit from targeted education - that vaccinations are preventative rather that curative, for example. However, mothers share a foundational goodwill towards vaccination and, all things being equal, would like their children to be vaccinated, with only a handful of exceptions. Given a sample of mothers who did not vaccinate their children, this finding is provocative: if mothers significantly value vaccines, why then did they not get their children vaccinated? We discovered that the answer lurks in how mothers perceive vaccination with respect to the priorities and responsibilities of everyday life, and in the seemingly mundane details of service design and execution. 


\section{Subsistence household economics: vaccinating as a low-involvement good}

Despite the mothers' general belief that vaccination is valuable for their infants, they did not prioritise vaccinating. To understand why this is so, we must situate the relative value of vaccination within their everyday life. Their worldview is structured by the binding constraints of childcare, family economics, informal markets and provisioning.

The vast majority of the Ethiopian mothers we interviewed are peasants who live just above a subsistence level. Families live in basic mud-walled huts and dress in severely worn garments. The only economically substantial goods visible in most homes were a few iron pans used to cook the national staple food, injera. Clothes, food, fuel, water and of course money were often in extremely short supply. Thus, the daily quest to sustain the household's basic requirements for living dominates mothers' strategies for organising their day.

Getting infants vaccinated requires concerted effort. It is not part of the mother's routine and so she must plan for it. The vaccination process takes at least half a day and often a full day that the mother must somehow fit into an already busy schedule. Mothers pragmatically evaluate the importance of vaccination against the demands of keeping the household afloat. Getting one's child vaccinated requires squeezing this ad hoc activity into the daily demands of her household, necessarily trading off an activity that is of central importance for the family:

I am destitute. I have no more money that is left for health service after spending my family's daily food. So my only chance is to use the free resource. With the help of God I use the vegetation [traditional medicine]. I didn't go to health centre not because I lack interest to go, it is rather lack of money ... How could I discuss vaccination while I am occupied with thinking about my daily needs like fetching water, collecting fire wood and the like. Mother, Sentama

Most husbands work as labourers on small farms or else large-scale cash crop farms that produce coffee and tea. A few husbands own a small parcel of land to farm. The wives of these men often work as well, for instance, labouring on coffee plantations or managing small shops. If their husbands are smallholder farmers, wives are required not only to work in the field but also to haul produce to sell at the market - up to four hours away on foot. On top of this, domestic tasks are particularly time consuming. Mothers spoke of how they have no time to think about vaccination because they were so busy collecting firewood and water. For some of the rural mothers interviewed, the back-breaking work of collecting and hauling firewood back to their village was one of the only ways they could make money.

Mothers also are primary caregivers for their other children and extended family who cannot be left at home. On average, the mothers interviewed had 3.4 children and so they must arrange for someone to look after their other children each time they go for a vaccination. In addition, mothers are often responsible for taking care of sick members of their extended family who required their care. For mothers lacking strong social networks, it is difficult for them to find this kind of assistance. This is particularly true for mothers who are new to an area (e.g. those who had moved to their husband's village) since they often have trouble establishing the kind of relationships that produce this kind of social support (Kiros \& White, 2004).

Thus, for mothers in near subsistence-level households, the day-to-day demands of life made taking time out for vaccinating a huge challenge. These mothers describe themselves as 'living a hand to mouth existence,' 'destitute' and 'too busy finding my 
daily bread to worry about vaccination.' Some mothers even expressed outrage that the interviewer could not understand that getting their children vaccinated was quite trivial compared to their daily travails. Interventions that hope to increase rates of immunisation must acknowledge these difficulties, and design vaccination services to suit.

In marketing terms, the non-vaccinating mothers we spoke to uniformly perceived vaccination to be a low-involvement good. Because the good (the vaccine in this case) is viewed as less valuable and less risky compared to the role of other activities and goods within their lifeworld context, the customer does not invest much time in the process of investigating the good, making a decision about it or pursuing its acquisition, despite its positive value. Marketing theory demonstrates that it is very difficult to change people's evaluation of the relative importance of such goods, so vaccine delivery must be designed and implemented with this low-involvement designation in mind (Berry, Seiders, \& Grewal, 2002).

\section{Service failures increase perceived cost to vaccinate}

Mothers also forge collective judgements about the effort required to vaccinate, and the characteristics of the vaccination experience. This is the other side of the calculated tradeoff that mothers routinely make. Mothers would be very likely to vaccinate, even though it is a low-involvement good, if doing so required little planning, did not disrupt the household economy, was predictable and offered a pleasant experience. But, unfortunately, mothers' shared perceptions of poor service delivery lead them to assign a 'cost to vaccinate' that is quite high. Most mothers believed that getting their child vaccinated would be an arduous, unpredictable and demeaning task, and would likely be costly in terms of lost household income. These perceptions, when weighed against the low prioritisation of vaccination, led them to decide not to vaccinate. A customer-centric service design approach identifies important failings in service provision and, so, provides an opportunity to improve aspects of provision that dissuade mothers from vaccinating their children.

\section{Unpredictable screening}

Mothers share a belief that, even if they make it to a clinic or session and find the location open and vaccines in stock, their child may well be refused vaccination. They tell stories about women who were told by health workers that their children could not be vaccinated because they were too young, underweight, sick or lacking the correct documentation. Ethiopia's national recommendations state that children should be given the pentavalent vaccine even if they are brought to a clinic well past the recommended immunisation dates $(6,10$ and 14 weeks), and that the vaccine should be administered to all children, even those who are visibly underweight or sickly. Yet, apparently there are enough improvised violations of these guidelines at the point of service to create the general perception amongst mothers that infants must meet strict criteria.

A common version of this problem occurs when mothers are forced to switch health facilities between birth and vaccination. It is a social norm in Ethiopia for first-time mothers to give birth in their parents' home. So mothers who have settled in a different area with their husbands had to use a different facility for vaccinating. Mothers believe that they would be denied vaccination because their child was born and registered in a different area. Some mothers believe that this was due to quota systems that existed at different facilities wherein a facility received only the requisite amount of vaccine for the children in its specific catchment. No such policy exists. However, health workers 
sometimes improvise such a policy because they receive irregular and unpredictable shipments and they know that it is very difficult to process ad hoc requests for additional supplies. Additionally, we observed that health workers, who are assessed according to the percentage of children in their catchment who have received the complete course of vaccines, worry that vaccinating non-local children might hurt their performance by increasing the number of children receiving only one of the three-vaccination course.

\section{Symbolic violence in the service encounter}

Mothers believe that vaccinating their children means that they will have to deal with harsh social class biases embedded in the service encounter. Mothers complained that they are made to wait for excessive periods simply to put them in their place. One mother described how her experience with the local health centre had led her to believe that 'the patient may die while the physicians hesitate to see the patient.' These waits are particularly demeaning because they are not caused by heavy demand on vaccination services. Rather mothers, especially those living in urban areas, describe a lackadaisical approach among health staff responsible for vaccination, taking long breaks and pretending to be in meetings, working very slowly, demonstrating more interest in chatting amongst themselves than delivering the vaccines. The mothers are frequently told to come back at a later date, only to face the same delays once again. This nonchalant approach is insulting because it devalues the time pressures and economic demands that the mothers are juggling to get the vaccination.

Forceful methods used by the authorities to ensure that all children were vaccinated can also have a pronounced impact on mother's perceptions of the vaccination service encounter. During polio campaigns, the police were called into action in Agaro Town to arrest and imprison mothers who had not allowed their children to receive the vaccination. Some mothers were told that their children would be denied access to education if they did not allow them to receive the polio vaccine. Because mothers do not easily differentiate between different types of vaccines, these draconian methods used for the polio campaign shaped mothers' general perceptions of vaccination delivery.

When mothers finally did receive service, they report that the interactions often take the form of harassment. They report that staff members aggressively challenge them on the exact age of the child, and question whether the child is well cared for at home. As a result, the poorest mothers spoke of their belief that vaccination is not a service that is relevant to them, saying it was for 'the upper strata' while characterising themselves as 'poor' or 'ignorant.':

\footnotetext{
They do not treat me well. There are lots of ups and downs and they demean patients. For instance, if I bring my child on the second or third day after he gets sick, they shout at me. They say 'why do you keep silent until the child deteriorates?' I keep silent because I thought he will get fine gradually. They don't have sense of empathy. They boast while patients are suffering. They say we are closed before the proper time. - Mother, Agaro Town

The reason why we don't take our children is the workers at the health centre don't admit us if we have missed the date of the appointment. They insult us for being late. So we fear to go there for vaccination because they offended us. - Mother, Omonada
}

The sociologist Pierre Bourdieu coined the term symbolic violence to characterise these routine expressions of class privilege that are embedded in everyday life (Bourdieu, 1991). The mothers' desire to avoid this symbolic violence was so intense that they often sought out private health care or relied upon traditional health care providers such as 
masseuses, despite their belief in the efficacy of vaccination and the relatively high cost of these alternative services. Crucially, many mothers chose not to get their child vaccinated specifically because they perceived that the administration of the vaccines was so authoritarian and degrading.

\section{Privileging the administrative worldview: vaccination cards}

This degrading experience was often sparked by conflicts when mothers lost or forgot their children's vaccination cards. Mothers described how staff often demanded vaccine cards with such forcefulness and condescension that they perceived that failure to bring the card would result in a rejection of services. Many mothers fail to retain these cards in Addis Ababa (Berhane \& Pickering, 1993); it is likely that the problem is considerably worse in Jimma, where only $55 \%$ of the mothers interviewed had received any formal education.

This is a good example of the tensions between the administrative logic that pervades vaccination delivery and a customer orientation. Vaccination cards are highly useful from an administrative view. They allow staff to ensure that all vaccinations have been received, and to chart the progress of children through the course of standard immunisations. But, due to the dominance of the administrative logic, staff members treat the proper management of vaccination cards as their primary objective, rather than the delivery of vaccines in a manner that encourages mothers to participate. Accordingly, they often react harshly towards mothers, whom they perceive as interfering with the proper administrative process. Mothers fear this well-known rebuke to the point that they decide not to vaccinate if they cannot locate their cards.

\section{Unpredictable outreach}

Although Ethiopia's recent Health Extension Programme has set aggressive targets for delivering continuous primary health care to distant communities, the most rural (and sometimes nomadic) populations still cannot be served by health outposts due to pragmatic logistical issues created by such dispersed and mobile populations. So outreach programmes are still needed to reach these populations. Service delivery for outreach is particularly precarious because it involves periodic long-distance trips to set up one-day clinics, which must be announced in advance.

These sessions are scheduled by the Health Extension Workers (HEWs) stationed at health outposts (and, for now, nurses working at health centres fill in for kebeles not yet serviced by HEWs). Rather than adhering to a regular schedule, HEWs tend to conduct these sessions when they have a chance to pick up vaccines from their nearest supply point. Similarly, nurses working at health centres will conduct outreach sessions when the necessary resources to cover the costs of the outreach session are in place. Nurses are supposed to be paid a per diem to cover their travel costs, but these payments are invariably late and unpredictable and are not linked to quality of service.

From the mothers' viewpoint, outreach services are very problematic because they are entirely unpredictable. The first step in the service delivery process is simply finding out that a vaccination session has been scheduled. Many rural mothers spoke of the difficulties they had encountered in determining the date and time of vaccination sessions. Mothers described how by the time they had heard there was a session and made logistical arrangements, the vaccinators had completed the session (Streefland et al., 1999). Communications for these events were informal, sporadic and often not given until the day of the event. Mothers complained that they had not heard the loudspeaker, or 
could not make arrangements on such short notice. Because vaccination is low involvement for the women, they do not proactively seek out information and engage in a significant search to make sure that their child gets into an outreach clinic. Mothers reported that even if they happened to hear about a session and were able to make time to attend, the vaccination sessions were very crowded and oversubscribed. The HEWs often closed the session or ran out of vaccines before all the children gathered were vaccinated.

\section{Designing EPI as a service}

Mothers did not vaccinate their infants because Ethiopia's vaccine delivery system has not been designed as an effective service responding to customer needs. Mothers believe that routine vaccines will benefit their children, but the perceived value is necessarily modest compared to the intensive demands of everyday life - vaccines are a lowinvolvement good. Therefore, generating high participation levels requires that the service imposes minimal costs on the mothers who must bring in their children for the vaccination. We document a number of perceived 'costs to vaccinate' (both economic and social) that lead mothers to make a pragmatic choice not to vaccinate. Vaccination rates can be substantially increased by focusing intensively on these service failures and redesigning the delivery system to correct for these failures, thereby lowering the perceived cost to vaccinate. For example, service design innovations that stem from this research might include the following:

- Base ISS economic incentives on metrics derived from mothers' satisfaction with vaccination services, rather than percentage increases in children vaccinated. Institute a hiring and promotion policy with HEWs based upon these satisfaction metrics.

- Institute a 'vaccination guarantee': If for any reason mothers are turned away when they bring their child to a facility, a worker will go to their home to do the vaccination. Publicise this guarantee widely.

- Redesign outreach programmes around a routine calendar that fits mothers' schedules (e.g. first Saturday of every month) and is publicised well in advance. Institute an outreach payment programme that is based upon completing each outreach day successfully rather than a per diem.

Despite the extraordinary resources that the global public health sector has devoted to improving vaccination rates in Ethiopia and other EPI countries, the service design problems that we have unearthed are ignored in current interventions. The administrative logic that dominates the sector obscures these customer-centred problems from view they are literally 'unthinkable' because the worldview of the mothers of children to be vaccinated is not now incorporated in what the sector defines as 'good management.' But good management is not just about the imposition of Western management, measurement and control techniques. The logic of service design opens up a new pathway to pursue improvements in vaccination rates, which deserve the same sort of concerted effort and funding as current administrative efforts.

\section{Acknowledgements}

This research was conducted while Douglas Holt was Chair of Marketing, Said Business School, University of Oxford, and Jacob McKnight was his research assistant. 


\section{Funding}

This project was supported by funding from the Paediatric Dengue Vaccine Initiative.

\section{References}

Berhane, Y., \& Pickering, J. (1993). Are reminder stickers effective in reducing immunization dropout rates in Addis Ababa, Ethiopia? The Journal of Tropical Medicine and Hygiene, 96(3), 139-145.

Berry, L. (1995). Relationship marketing of services - growing interest, emerging perspectives. Journal of the Academy of Marketing Science, 23, 236-245. doi:10.1177/009207039502300402

Berry, L., \& Parasuraman, A. (1991). Marketing services. New York, NY: Free Press.

Berry, L., Seiders, K., \& Grewal, D. (2002). Understanding service convenience. The Journal of Marketing, 66(3), 1-17. doi:10.1509/jmkg.66.3.1.18505

Bourdieu, P. (1991). Language and symbolic power. Cambridge, MA: Harvard University Press.

Brugha, R., Starling, M., \& Walt, G. (2002). GAVI, the first steps: Lessons for the Global Fund. The Lancet, 359, 435-438. doi:10.1016/s0140-6736(02)07607-9

Burawoy, M. (1998). The extended case method. Sociological Theory, 16(1), 4-33. doi:10.1111/ 0735-2751.00040

Cheyne, J. (1989). Vaccine delivery management. Reviews of Infectious Diseases, 11, S617-S622.

Closser, S. (2010). Chasing polio in Pakistan: why the world's largest public health initiative may AQ3, fail. Nashville, TN: Vanderbilt University Press.

Cottam, H., \& Leadbetter, C. (2004). Health: Co-creating services. London: Design Council.

Donnelly, J. (2011). Ethiopia gears up for more major health reforms. The Lancet, 377, 1907-1908. doi:10.1016/S0140-6736(11)60795-2

Farmer, P. (1996). On suffering and structural violence: A view from below. Daedalus, 125, 261-283.

Farmer, P. (2004). An anthropology of structural violence. Current Anthropology, 45, 305-325. doi: $10.1086 / 382250$

Ferguson, J. (1994). The anti-politics machine. "development", depoliticization and bureaucratic power in Lesotho. Minneapolis: University of Minnesota Press.

Foucault, M., Burchell, G., Gordon, C., \& Miller, P. (1991). The Foucault effect: Studies in governmentality, with two lectures by and an interview with Michel Foucault. Chicago, IL: University of Chicago Press.

GAVI. (2002). Progress report: Reaching every district. Geneva: Author.

GAVI. (2005a). GAVI Alliance progress report. Geneva: Author.

GAVI. (2005b). Proposal for GAVI to invest in health systems strengthening (HSS) support. Geneva: Author.

GAVI. (2007). Health systems strengthening (HSS) support update. Geneva: Author.

GAVI. (2008). GAVI Alliance handbook. Geneva: Author.

GAVI. (2010). GAVI Alliance board backs funding platform for stronger health systems. Geneva: Author.

Glaser, B. G., \& Strauss, A. L. (1968). The discovery of grounded theory: Strategies for qualitative research. London: Weidenfeld and Nicolson.

Griffin, A., \& Hauser, J. R. (1993). The voice of the customer. Marketing Science, 12(1), 1-27.

Justice, J. (1986). Policies, plans, \& people: Culture and health development in Nepal. Berkeley: University of California Press.

Kiros, G. E., \& White, M. J. (2004). Migration, community context, and child immunization in Ethiopia. Social Science \& Medicine, 59, 2603-2616. doi:10.1016/j.socscimed.2004.04.009

Leach, M., \& Fairhead, J. (2007). Vaccine anxieties. London: Earthscan.

Lounsbury, M., \& Crumley, E. T. (2007). New practice creation: An institutional perspective on innovation. Organization Studies, 28, 993-1012. doi:10.1177/0170840607078111

McCracken, G. (1988). The long interview. Thousand Oaks, CA: Sage.

McKinsey and Company. (2003). Achieving our immunization goal: Final report. Washington, DC: McKinsey and Company.

Nguyen, V.-K. (2010). The republic of therapy: Triage and sovereignty in West Africa's time of AQ4 AIDS. Durham, NC: Duke University Press.

Nichter, M. (1995). Vaccinations in the third world: A consideration of community demand. Social Science \& Medicine, 41, 617-632. doi:10.1016/0277-9536(95)00034-5 
Rajaratnam, J. K., Marcus, J. R., Flaxman, A. D., Wang, H., Levin-Rector, A., Dwyer, L., ... Murray, C. J. L. (2010). Neonatal, postneonatal, childhood, and under-5 mortality for 187 countries, 1970-2010: A systematic analysis of progress towards Millennium Development Goal 4. The Lancet, 375, 1988-2008. doi:10.1016/S0140-6736(10)60703-9

Sanou, A., Simboro, S., Kouyate, B., Dugas, M., Graham, J., \& Bibeau, G. (2009). Assessment of factors associated with complete immunization coverage in children aged 12-23 months: A cross-sectional study in Nouna district, Burkina Faso. BMC International Health and Human Rights, 9(Suppl 1), S10. doi:10.1186/1472-698X-9-S1-S10

Scott, J. (1998). Seeing like a state: How certain schemes to improve the human condition have failed. New Haven, CT: Yale University Press.

Streefland, P., Chowdhury, A., \& Ramos-Jimenez, P. (1999). Patterns of vaccination acceptance. Social Science \& Medicine, 49, 1705-1716. doi:10.1016/S0277-9536(99)00239-7

Thomas, E. (2008). Innovation by design in public services. London: The Guardian.

Thompson, C. J. (1997). Interpreting consumers: A hermeneutical framework for deriving marketing insights from the texts of consumers' consumption stories. Journal of Marketing Research, 34, 438-455.

Thompson, C. J., Pollio, H. R., \& Locander, W. B. (1994). The spoken and the unspoken: A hermeneutic approach to understanding the cultural viewpoints that underlie consumers' expressed meanings. The Journal of Consumer Research, 21, 432-452.

Wiysonge, C. S., Uthman, O. A., Ndumbe, P. M., \& Hussey, G. D. (2012). Individual and contextual factors associated with low childhood immunisation coverage in sub-Saharan Africa: A multilevel analysis. PLoS One, 7(5), e37905. doi:10.1371/journal.pone.0037905 